Résumés des conférences et travaux

\title{
Hébreu qoumrânien et dialectes araméens
}

\section{Ursula Schattner-Rieser}

\section{(2) OpenEdition}

Journals

Édition électronique

URL : https://journals.openedition.org/ashp/637

DOI : 10.4000/ashp.637

ISSN : 1969-6310

Éditeur

Publications de l'École Pratique des Hautes Études

\section{Édition imprimée}

Date de publication : 1 octobre 2009

Pagination : 41-42

ISSN : 0766-0677

\section{Référence électronique}

Ursula Schattner-Rieser, "Hébreu qoumrânien et dialectes araméens ", Annuaire de l'École pratique des hautes études (EPHE), Section des sciences historiques et philologiques [En ligne], 140 | 2009, mis en ligne le 06 octobre 2009, consulté le 06 juillet 2021. URL : http://journals.openedition.org/ashp/637 ; DOI : https://doi.org/10.4000/ashp.637 


\title{
HÉBREU QOUMRÂNIEN ET DIALECTES ARAMÉENS
}

\author{
Chargée de conférences : $\mathrm{M}^{\mathrm{me}}$ Ursula SCHATTNER-RIESER
}

Programme de l'année 2007-2008 : Traditions araméennes et hébraïques concernant le patriarche Noé et le livre perdu.

Tout d'abord ont été étudiés les passages qui parlent de la naissance miraculeuse de Noé, l'élu de Dieu et arrière petit-fils du patriarche Enoch.

Après une introduction sur les « livres perdus » en général, en commençant tout d'abord par ceux de la Bible qui mentionnent dans cinquante passages une vingtaine de livres «perdus », dont nous citons à titre d'exemple « Le livre des Guerres de YHWH » mentionné en Nb 21, 14, « Le livre du Juste » (Jos 10, 13; 2S 1, 18), «Les annales du roi David » (1Ch 27, 24), « Le livre des actes de Salomon » (1R 11, 41), « Le livre des annales des rois d'Israël » (1R 14, 19; 15, 31; 16, 5.14.20.27; 22, 39;

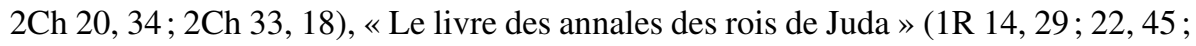
$15,7.23)$.

Les Apocryphes aussi mentionnent des livres disparus, dont «Le livre de Noé mentionné dans 1QapGén et 1Enoch, Jub, ALD Koutloumous 39, les Chroniques samaritaines, Zohar); «Le livre d'Énoch », (1Enoch de Qumrân en araméen et grec et en éthiopien, Jubilées); «Les annales de Jean Hyrcan » (1Macc 16, 24); «Divers documents écrits » Test de Job 40, 14; 41, 6; 50, 3; « Le livre d'Adam ».

Dans une ancienne liste sur les écrits non-canoniques, attribuée à Athanase d'Alexandrie (296-373) l'auteur inclut nombre d'apocryphes, dont les livres : d'Enoch, des Patriarches, La prière de Joseph, Le testament de Moïse, L'ascension de Moïse, Les pseudépigraphes d'Abraham, d'Eldad et Modad, d'Élie le Prophète, de Sophonie le Prophète, de Baruch, etc.

Ensuite nous avons abordé le sujet du programme proprement dit, c'est-à-dire la recherche sur Le livre perdu de Noé.

Nous avons commencé par l'examen des passages extraits du rouleau araméen de l'Apocryphe de la Genèse (1QapGen) de la première grotte de Qoumrân. Ensuite nous avons étudié les textes physiognomoniques (4Q534-4Q536 Élu de Dieu ou Naissance de Noé) qui devraient être situés dans un contexte plus large avec prise en considération d'un axe énochide-noachide, puisqu'il existe un récit parallèle dans le manuscrit 4Q204 du cycle d'Énoch que l'on connaissait déjà de la version éthiopienne de 1Enoch (chap. 106), ou le livre fait partie du canon de l'Église éthiopienne. Les manuscrits 4Q534 - 4Q535 - 4Q536 peuvent être rapprochés des traditions hénochiques relatant la naissance miraculeuse et les qualités exceptionnelles de Noé : 1Enoch 106-107; 1Q20 V-VI. Mais compte tenu de l'état fragmentaire des manuscrits, il n'est cependant pas possible de confirmer que les fragments 4Q534 - 4Q535 - 4Q536 appartiennent au «Livre des paroles de Noé » mentionné en 1Q20 V 29 et dans plusieurs sources 
anciennes $^{1}$. Le fragment 4Q534 frag. 1 col. i 5 mentionne que le personnage qualifié d'Élu de Dieu connaîtra les « trois livres ».

En ce qui concerne la nature de ces trois livres et leur contenu, il existe deux hypothèses. L'une, de P. Grelot (« Hénoch et ses écritures », RB, 82 [1975], p. 481-500), rapproche ces trois livres de ceux mentionnés en Jubilés 4, 17-24, en relation avec Hénoch : le Livre astronomique, le Livre des songes et le Livre des Veilleurs. Pourtant, le livre des Jubilés ne parle pas explicitement de trois livres, mais de plusieurs écrits contenus dans un seul livre. La seconde hypothèse s'appuie sur les affinités textuelles de 4Q534-536 avec plusieurs textes samaritains. Si on ne peut affirmer avec certitude que l'ensemble 4Q534-536 est un texte proto-samaritain, il convient de mentionner que seules les traditions samaritaines ont conservé le souvenir des trois livres transmis à Noé. On les trouve cités dans plusieurs pseudo-chroniques : le Kitab al-asatir ou «Les secrets de Moïse », commentaire légendaire (Midrash) sur la vie des Patriarches (cf. J. T. Milik, «Écrits préesséniens de Qumrân : d'Hénoch à Amram », dans M. Delcor [éd.], Qumrân : sa piété, sa théologie et son milieu, Paris - Louvain, 1978, p. 91-106); la Chronique Adler. Ces ouvrages précisent que Noé étudia avec Adam les mathématiques et trois livres : le Livre des signes / lettres, le Livre de l'astronomie et le Livre de la guerre (cf. E.-N. Adler et M. Seligsohn, Une nouvelle chronique samaritaine, Paris, 1903, p. 6; A. Neubauer, « Chronique samaritaine suivie d'un appendice contenant de courtes notices sur quelques autres ouvrages samaritains », Journal asiatique, 14 [1869], p. 385-470, spécialement p. 392).

Ensuite a été abordée la «biographie » de Noé qui est racontée dans 1QapGen colonnes V et VI et un passage parallèle, le fragment 4QElu de Dieu (4Q534).

1. Les spécialistes sont divisés quant au contenu - voire de l'existence même - de ce Livre de Noé; certains affirment qu'il transmettait l'épisode de la naissance miraculeuse de Noé (F. García Martínez), d'autres rejettent cette hypothèse (cf. la récente étude de W. Baxter, p. 193-194). 